\section{Kathepsin K}

H.-D. Haubeck

Wasserburg, Deutschland

\section{Englischer Begriff cathepsin K}

Definition Kathepsin K wird von Osteoklasten sezerniert und spielt eine wichtige Rolle bei der Degradation des TypI-Kollagens der Knochenmatrix.

Beschreibung Die Regulation des Knochenumbaus erfolgt durch die abgestimmte Aktivität von Osteoblasten und Osteoklasten. Kollagen Typ I, der quantitativ wichtigste (>90\%) Bestandteil der organischen Matrix des Knochens, wird während der Knochenresorption durch die Cysteinprotease Kathepsin $\mathrm{K}$ und verschiedene MatrixMetalloproteinasen (MMP) abgebaut. Hierbei lagern sich zunächst die Osteoklasten an die mineralisierte Knochenoberfläche an und senken, durch Carboanhydrase-II vermittelte Sekretion von Protonen, in einem abgeschlossenen Bereich an der Oberfläche den pH-Wert ab. Hierdurch und durch die Wirkung saurer Phosphatasen wird die mineralische Matrix aufgelöst. Anschließend kann Kathepsin K die organische Matrix und insbesondere Kollagen Typ I abbauen. Hierbei entstehen eine Reihe von Kollagen-Typ-I-Fragmenten, u. a. das carboxyterminale Kollagen Typ-I-Telopeptid (CTx). Anschließend können, nach Anhebung des pH-Werts verschiedene MMP den Abbau der organischen Matrix abschließen.

Die Bedeutung von Kathepsin K, das überwiegend von Osteoklasten exprimiert wird, für die Knochenresorption ergibt sich aus dem Phänotyp der Kathepsin-K-defizienten (Knockout-)Maus mit Kleinwuchs, Knochenfragilität, Osteosklerose und verschiedenen Knochendeformationen. Der Phänotyp entspricht dem der humanen Pycnodysostosis, bei der verschiedene Mutationen im Kathepsin-K-Gen gezeigt werden konnten.

Entsprechend der Funktion von Kathepsin K bei der Knochenresorption eignet sich Kathepsin K, wie die KollagenTyp-I-Fragmente CTx, NTx, CrossLaps, Helical Peptide und Desoxypyridinolin, grundsätzlich als Marker des Knochenumbaus bzw. des Knochenabbaus. Für Kathepsin K steht seit Kurzem ein Enzymimmunoassay zur Verfügung.

\section{Literatur}

Fujita Y, Nakata K, Yasui N et al (2000) Novel mutations of the cathepsin $\mathrm{K}$ gene in patients with pycnodysostosis and their characterization. J Clin Endocrinol Metab 85:425-431

Garnero P, Ferreras M, Karsdal MA et al (2003) The type I collagen fragments ICTP and CTX reveal distinct enzymatic pathways of bone collagen degradation. J Bone Miner Res 18:859-867 